\title{
Ketenylidene-1,4-cyclohexadiene: preparation of a divinylketene and reaction with the aminoxyl radical TEMPO
}

\author{
Kazem Saidi ${ }^{\#}$ and Thomas T. Tidwell* \\ \#Department of Chemistry, Shahid Bahonor University of Kerman, Kerman 76169, Iran \\ *Department of Chemistry, University of Toronto, Toronto, Ontario M5S 3H6 Canada \\ E-mail: ttidwell@chem.utoronto.ca
}
Dedicated to Professor Oswald S. Tee on the occasion of his $60^{\text {th }}$ birthday, and in recognition of his contributions to chemistry in Canada
(received 17 Aug 01; accepted 17 Nov 01; published on the web 25 Nov 01)

\begin{abstract}
Reaction of 1,4-cyclohexadienyl-3-carbonyl chloride 17 with 1,8-bis(dimethylamino) naphthalene 6 gave the divinylketene ketenylidene-1,4-cyclohexadiene $\mathbf{1 4}$ as identified by the IR band at $2101 \mathrm{~cm}^{-1}$. Reaction of 14 with tetramethylpiperidinyloxyl (TEMPO, TO•) gives N2,2,6,6-tetramethylpiperidinyl benzoate 18 formed from the radical 19 resulting from TEMPO attack on the carbonyl carbon of 14.
\end{abstract}

Keywords: Divinylketene, aminoxyl radical, TEMPO, ketenylidene-1,4-cyclohexadiene

\section{Introduction}

In 1992 we reported a computational study of the fulvenones $1-3{ }^{1 \text { a }}$ On the basis of isodesmic comparisons 1 was found to be destabilized by $17.1 \mathrm{kcal} / \mathrm{mol}$, and as illustrated by the comparison of eq 1 pentafulvenone 2 is stabilized by $5.7 \mathrm{kcal} / \mathrm{mol}$, whereas heptafulvenone 3 is destabilized by $5.1 \mathrm{kcal} / \mathrm{mol}$ (eq 2). ${ }^{1}$ These effects were attributed ${ }^{1}$ to the high electron density at $\mathrm{C} \beta$ of the the ketenyl group, which gives 2 the character of a $6 \pi$-electron aromatic system, whereas 1 has the character of an $4 \pi$-antiaromatic system, and 3 has the character of an $8 \pi$ electron antiaromatic ring.

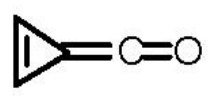

1

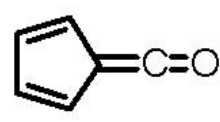

2

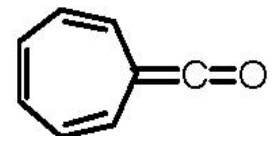

3 


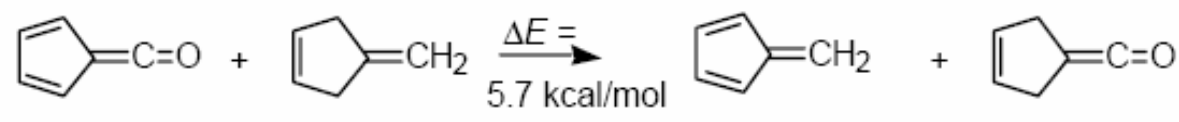

2

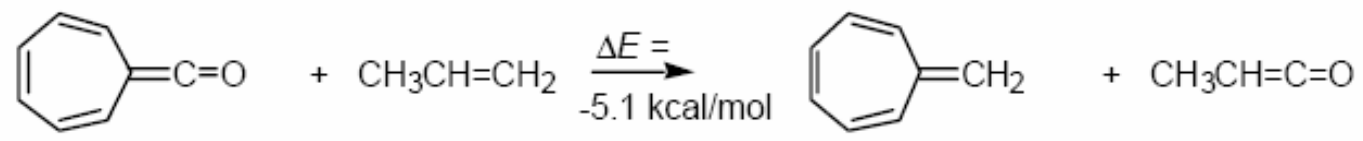

3

Recently we have undertaken the study of radical reactions of ketenes, ${ }^{2}$ and predicted on the basis of B3LYP/6-31G* calculations that the reaction of $\mathrm{H} 2 \mathrm{NO} \cdot$ with $\mathrm{CH} 2=\mathrm{C}=\mathrm{O}$ at the $\alpha$-carbon would be exothermic by $18.7 \mathrm{kcal} / \mathrm{mol}$ (eq 3). ${ }^{2 \mathrm{a}}$ This prediction was confirmed experimentally by the discovery that ketenes such as phenylketene 4 undergo facile reaction with the aminoxyl radical tetramethylpiperidinyloxyl (TEMPO) forming 1,2 bis(addition) products (eq 4), or in some cases products resulting from allylic rearrangements, cyclizations, or free radical rearrangements. ${ }^{2}$ These reactions were all interpreted as involving rate limiting attack of TEMPO on the carbonyl carbon as shown in eq 4 , and in the case of 4 this was followed by fast capture of the resulting radical by a second TEMPO. ${ }^{2 b, c}$
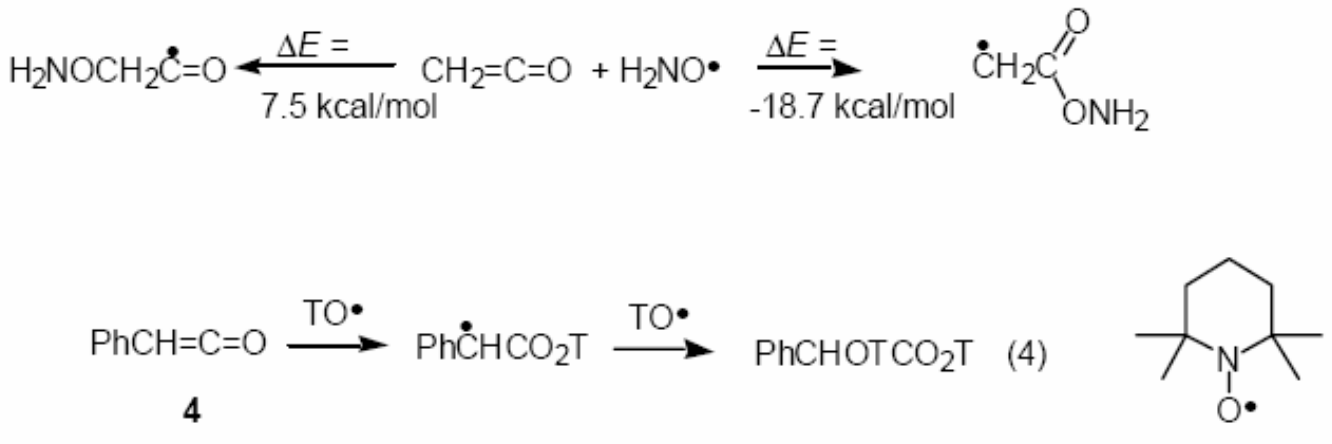

TEMPO (TO•)

Heptafulvenone 3 had previously ${ }^{4 a}$ been generated by the reaction of eq 5 , and the structure of 3 was established by formation of characteristic trapping products. To prepare this species for direct observation we utilized new methodology developed by Lectka, et al, ${ }^{4 b}$ using 1,8 bis(dimethylamino)naphthalene $\mathbf{6}$ as a base together with catalytic $\mathrm{Et}_{3} \mathrm{~N}$ for the dehydrohalogenation of acyl chlorides. This process worked well for the preparation of 3 (eq 6), which displayed an IR band at $2101 \mathrm{~cm}^{-1}$, and reacted with TEMPO to produce the interesting group of products 7 and 8 (eq 7). ${ }^{2 \mathrm{e}}$ A possible mechanism for this process is shown in Scheme 1. 


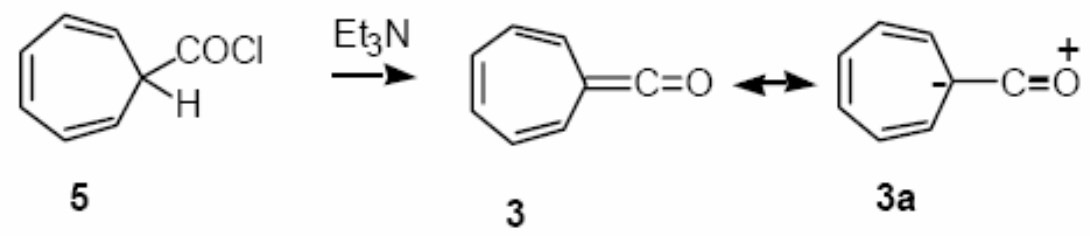<smiles>CN(C)c1cccc2cccc(N(C)C)c12</smiles><smiles>CC(C)c1ccc(C=O)c(C(=O)[O-])c1</smiles>

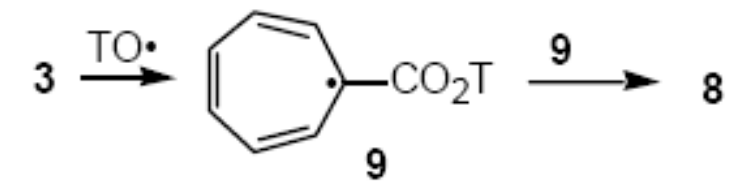

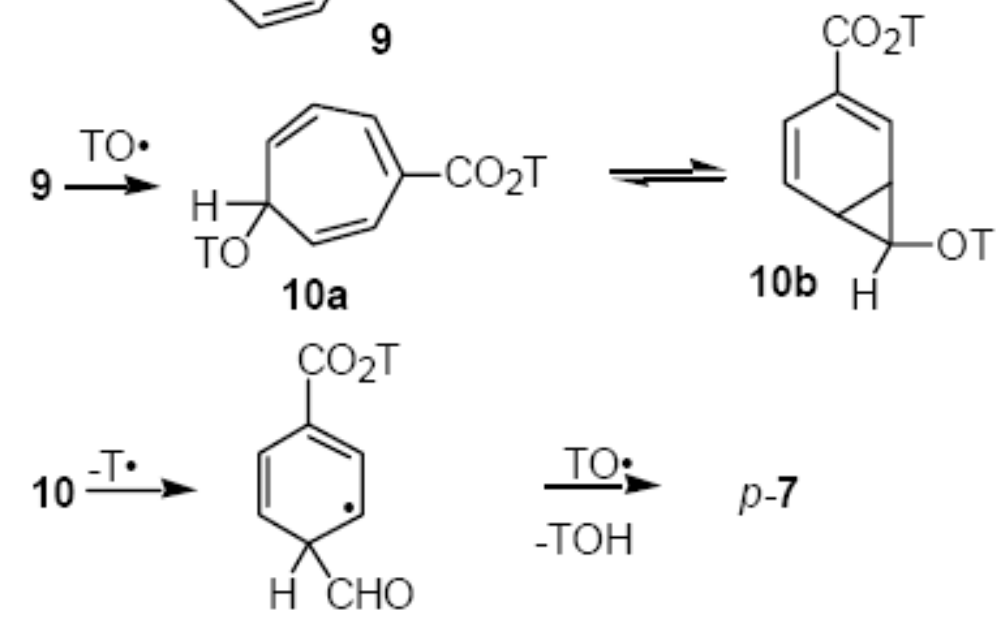

\section{Scheme 1}

This study of alkenylketenes was extended to the compounds 11-13, all of which were identified by IR, and gave interesting reactions with TEMPO (eq 8-10). ${ }^{2 \mathrm{e}}$ The $\alpha$-hydrogens of each of these acyl chlorides are quite acidic and the generation of these ketenes was facile. In addition pentafulvenone 2 was generated by Wolff rearrangement and directly observed by IR, 
and reacted with TEMPO forming surprising products (eq 11). ${ }^{2 \mathrm{~g}}$<smiles></smiles>

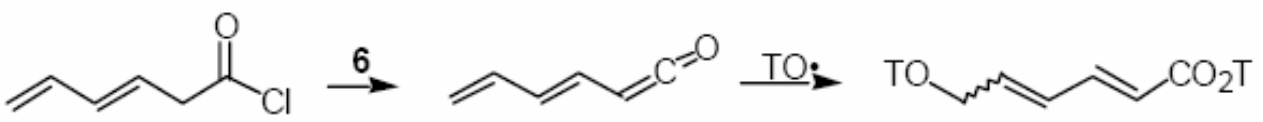

12<smiles></smiles><smiles>O=C=C1C=CC=C1</smiles>

Because of the success of these studies of fulvenones and alkenylketenes it appeared desirable to extend the studies to divinylketenes. These have recently been the subject of experimental studies in which substituted divinylketenes have been generated as unobserved intermediates by the thermolysis of 2-vinylcyclobutenones (eq 12). ${ }^{3}$ However such divinylketenes have not been directly observed.

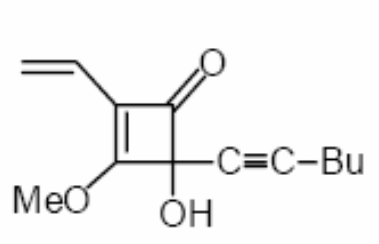<smiles>C=CC(=C=O)/C(C#CCBr)=C(\O)C(C)C</smiles><smiles>C=CC1=C(OC)C(=O)C=C(CCCCC)C1=O</smiles>

Previously ${ }^{1 a}$ we have calculated the structures and energies of divinylketenes 14 and 15 at the $\mathrm{HF} / 6-31 \mathrm{G} * / / \mathrm{HF} / 6-31 \mathrm{G}^{*}$ level, and these calculations permit the derivation of the isodesmic relations in eqs 13-17. These comparisons reveal that vinyl groups and alkyl groups have equivalent effects on the stability of ketenes (eq 14-16), but that ketenylidene-1,4cyclohexadiene 14 is destabilized relative to divinylketene by $3.8 \mathrm{kcal} / \mathrm{mol}$ (eq 13), and by 7.9 $\mathrm{kcal} / \mathrm{mol}$ relative to pentafulvenone 2 (eq 17). 


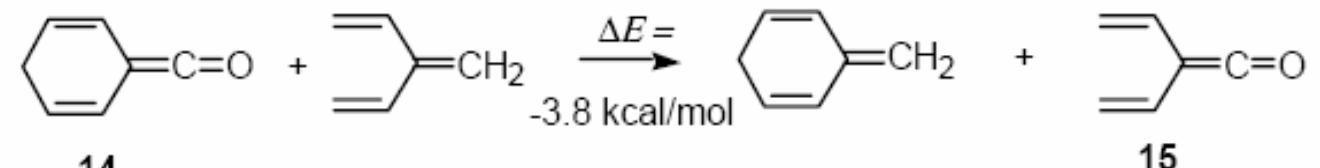

14

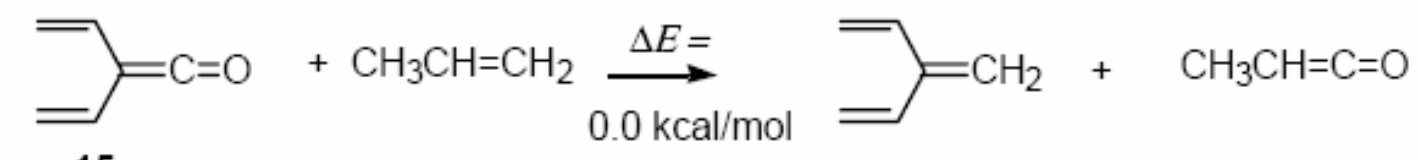

15

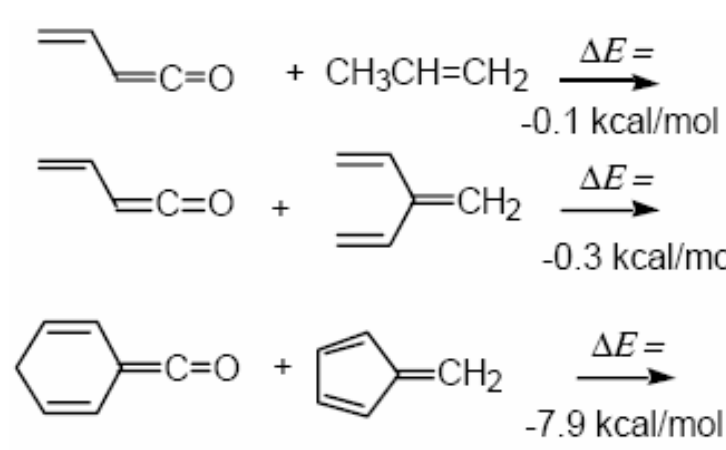

14

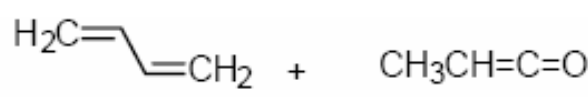<smiles>C=CC=CC(=O)C=C</smiles>

15

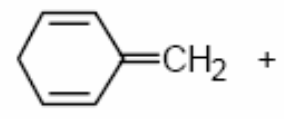

\section{Results and Discussion}

These previous studies indicate that the generation, direct observation, and reaction of divinylketenes would be of great interest. We have therefore directed our efforts to the study of 14.

Birch reduction of benzoic acid provided a convenient route to cyclo-1,4-hexadiene-3carboxylic acid (16), ${ }^{5 \mathrm{a}}$ which was converted to the acid chloride $17^{5 \mathrm{~b}}$ with $\mathrm{SOCl}_{2}$ (eq 18). Reaction of 17 with 6 and catalytic $\mathrm{Et}_{3} \mathrm{~N}$ in toluene at $-78{ }^{\circ} \mathrm{C}$ gave immediate formation of a yellow color with a precipitate, and an IR band at $2101 \mathrm{~cm}^{-1}$ attributed to the ketene 14 was observed (eq 19). Addition of TEMPO led to the formation of N-2,2,6,6-tetramethylpiperidinyl benzoate (18), ${ }^{5 \mathrm{c}}$ identified by its spectral properties and by comparison to an authentic sample prepared from benzoyl chloride and tetramethylpiperidinol. ${ }^{5 \mathrm{~d}}$ 


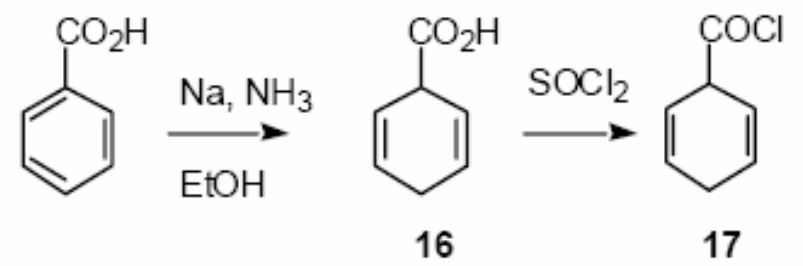<smiles>CC(C)C1=CCC=CC1=C=O</smiles>

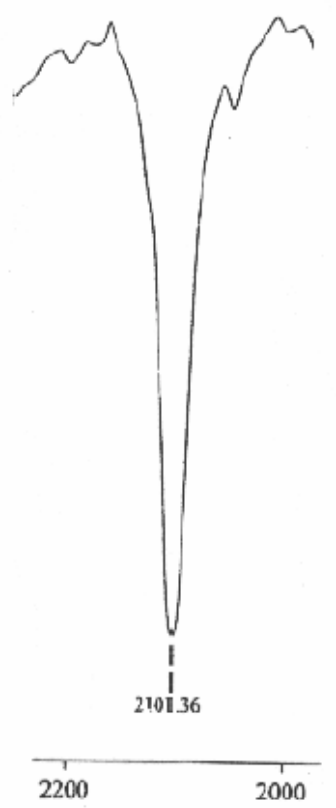

Fig 1. IR Spectrum of 14

A possible route to $\mathbf{1 8}$ is shown in eq 20. Alternatively TEMPO could add to the intermediate radical 19 forming $\mathbf{2 0}$ which undergoes loss of $\mathrm{TOH}$. 


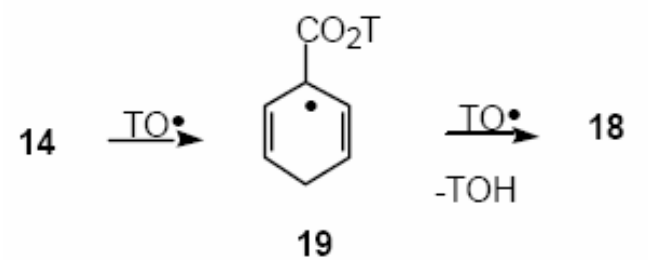

19<smiles>O=C([O-])C1=CC([TlH])CC=C1</smiles>

20

Thus the divinylketene $\mathbf{1 4}$ is readily available by the route of eqs 18 and 19, and reacts with TEMPO as shown in eq 20. Because of its multple functionality 14 may also be expected to react readily with nucleophiles, electrophiles, and cycloaddition reagents, and to lead to interesting and useful products.

The destabilization of $\mathbf{1 4}$ relative to divinylketene $\mathbf{1 5}$ as indicated by eq 13 is also striking, and merits further consideration. In the absence of further information the analysis of this problem is highly speculative, but it may be noted that vinylketene has a significant conjugative interaction as depicted in 21, as evidenced by its dipole moment ${ }^{6 \mathrm{a}}$ and ${ }^{13} \mathrm{C} \mathrm{NMR}$ spectrum. ${ }^{6 \mathrm{~b}}$ The constrained divinylketene $\mathbf{1 4}$ is cross-conjugated, and the second vinyl group might be destabilizing in this geometry, whereas in the acylic divinylketene $\mathbf{1 5}$ it might be possible to avoid this problem. However further work would be required to resolve this question.

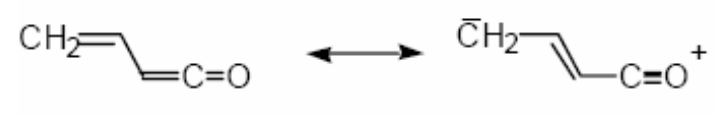

21

\section{Experimental Section}

General Procedures. Reactions were carried out under an atmosphere of argon or nitrogen. ${ }^{1} \mathrm{H}$ NMR spectra were obtained at $400 \mathrm{MHz}$ (Varian Unity instrument). ${ }^{13} \mathrm{C}$ NMR spectra were obtained at $125 \mathrm{MHz}$ (Varian Unity). IR spectra were obtained on a Perkin-Elmer FT-IR Spectrum 1000 spectrometer. Chromatography was carried out using silica gel.

Preparation of 3-ketenylidene-1,4-cyclohexadiene (14). To cyclohexadienyl carbonyl chloride $(15)^{5 \mathrm{~b}}(100 \mathrm{mg}, 0.706 \mathrm{mmol})$ and $6(151 \mathrm{mg}, 0.706 \mathrm{mmol})$ in $6 \mathrm{~mL}$ toluene at $-78{ }^{\circ} \mathrm{C}$ was added Et3N $(10 \mu \mathrm{L})$, with formation of precipitate and yellow color. An IR band at $2101 \mathrm{~cm}^{-1}$ for 14 was observed. TEMPO (220 mg, $1.41 \mathrm{mmol})$ in $1 \mathrm{~mL}$ toluene was added and the solution was 
stirred overnight at $25{ }^{\circ} \mathrm{C}$, filtered and concentrated. After acidification with $1 \mathrm{~N} \mathrm{HCl}$ the residue was extracted with ether, which was washed, dried, and concentrated. Chromatography $(25 \%$ EtOAc/hexane) gave $\mathbf{1 8}^{5 \mathrm{c}}$ as an oil $(120 \mathrm{mg}, 46 \mathrm{mmol}, 65 \%) .{ }^{1} \mathrm{H}$ NMR $\left(\mathrm{CDCl}_{3}\right) \delta 1.12(\mathrm{~s}, 6$,

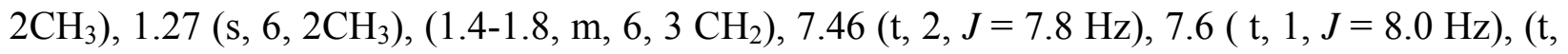
$2, J=8.0 \mathrm{~Hz}) .{ }^{13} \mathrm{C} \mathrm{NMR}\left(\mathrm{CDCl}_{3}\right) \delta 17.2,21.1,32.0,39.2,61.0,128.7,129.8,133.1,166.4$ (one signal not resolved). IR $\left(\mathrm{CDCl}_{3}\right) 1744 \mathrm{~cm}^{-1}$. EIMS m/z $261\left(9, \mathrm{M}^{+}\right), 246$. HREIMS $\mathrm{m} / \mathrm{z}$ calcd for $\mathrm{C}_{16} \mathrm{H}_{23} \mathrm{NO}^{2} 261.1735$, found 261.1729.

\section{Acknowledgements}

Financial support by the Natural Sciences and Engineering Research Council of Canada is gratefully acknowledged.

\section{References and Notes}

1. (a) McAllister, M. A.; Tidwell, T. T. J. Am. Chem. Soc. 1992, 114, 5362. (b) Gong, L.; McAllister, M. A.; Tidwell, T. T. J. Am. Chem. Soc. 1991, 113, 6021.

2. (a) Huang, W.; Henry-Riyad, H.; Tidwell, T. T. J. Am. Chem. Soc. 1999, 121, 3939. (b) Allen, A. D.; Cheng, B.; Fenwick, M. H.; Huang, W.; Missiha, S.; Tahmassebi, D.; Tidwell, T. T. Org. Lett. 1999, 1, 693. (c) Allen, A. D.; Cheng, B.; Fenwick, M. H.; Givehchi, B.; Henry-Riyad, H.; Nikolaev, V. A.; Shikhova, E. A.; Tahmassebi, D.; Tidwell, T. T.; Wang, S. J. Org. Chem. 2001, 66, 2611. (d) Allen, A. D.; Fenwick, M. H.; Henry-Riyad, H.; Tidwell, T. T. J. Org. Chem 2001, 66, 5759. (e) Fenwick, M. H.; Tidwell. T. T. Eur. J. Org. Chem. 2001, 3415. (f) Allen, A. D.; Rangwalla, H.; Saidi, K.; Tidwell, T. T.; Wang, J. Russ. Chem. Bull. 2001, in press. (g) Allen, A. D.; Henry-Riyad, H.; Porter, J.; Tahmassebi, D.; Tidwell, T. T. J. Org. Chem. 2001, 66, 1420.

3. (a) Xu, S.; Yerxa, B. R.; Sullivan, R. W.; Moore, H. W. Tetrahedon Lett. 1991, 32, 1129. (b) Liu, H.; Tomooka, C. S.; Xu, S. L.; Yerxa, B. R.; Sullivan, R. W.; Moore, H. W. Org. Synth. 1998, 76, 189. (c) Lee, K. H.; Moore, H. W. J. Org. Chem. 1995, 60, 735.

4. (a) Asao, T.; Morita, N.; Kitahara, Y. J. Am. Chem. Soc. 1972, 94, 3655. (b) Taggi, A. E.; Hafez, A. M.; Wack, H.; Young, B.; Drury, W. J., III; Lectka, T. J. Am. Chem. Soc. 2000, 122, 7831 .

5. (a) Kuehne, M. E.; Lambert, B. F. Org. Synth. 1973 Vol. V, p 400. (b) Hutter, W.; Bodenseh, H.-K.; Koch, A. J. Mol. Struct. 1994, 319, 73. (c) Crich, D.; Chen, C.; Hwang, J.T.; Yuan, H.; Papadatos, A.; Walter, R. I. J. Am. Chem. Soc. 1994, 116, 8937. (d) HenryRiyad, H. unpublished results in this laboratory.

6. (a) Brown, R. D.; Godfrey, P. D.; Woodruff, M. Austr. J. Chem. 1979, 32, 2103. (b) Trahanovsky, W. S.; Surber, B. W.; Wilkes, M. C.; Preckel, M. M. J. Am. Chem. Soc. 1982, 104, 6779 . 